\title{
BOTULINUM TOXIN A IN THE TREATMENT OF BLEPHAROSPASM
}

\section{A 10-year experience}

\author{
Laura Silveira-Moriyama1, Lilian R. Gonçalves', Hsin Fen Chien', Egberto R. Barbosa²
}

\begin{abstract}
To evaluate the long-term effect of botulinum toxin type A (BTX) in the treatment of blepharospasm, a retrospective analysis was conducted from the patients seen at the Movement Disorders Clinic of the Department of Neurology, Hospital das Clínicas, University of São Paulo School of Medicine from 1993 to 2003. A total of 379 treatments with BTX were administered to 30 patients with blepharospasm. Sixty six per cent of the subjects had used oral medication for dystonia and only $15 \%$ of them reported satisfactory response to this treatment. Ninety three per cent of the patients showed significant improvement after the first BTX injection. There was no decrement in response when compared the first and the last injection recorded. Adverse effects, mostly minor, developed at least once in $53 \%$ of patients. Six patients $(20 \%)$ discontinued the treatment but there was no case of secondary resistance.
\end{abstract}

KEY WORDS: botulinum toxin, blepharospasm, dystonia.

\begin{abstract}
Toxina botulínica tipo A no tratamento do blefaroespasmo: experiência de 10 anos de utilização
RESUMO - Para avaliar os efeitos a longo prazo da toxina botulínica tipo A (BTX) no tratamento do blefaroespasmo foi realizado estudo retrospectivo no Ambulatório de Distúrbios do Movimento da Clínica Neurológica do Hospital das Clínicas da Faculdade de Medicina da Universidade de São Paulo de 1993 a 2003. Um total de 379 aplicações de BTX foram administradas a 30 pacientes com blefaroespasmo. Previamente ao tratamento com toxina botulínica $63 \%$ dos pacientes utilizaram medicação oral para blefaroespasmo, mas apenas $15 \%$ referiu resposta satisfatória a este tratamento. Noventa e três por cento dos pacientes tiveram resposta significativa à primeira aplicação de BTX. Não houve decremento na resposta quando comparada a primeira à última aplicação registrada dos pacientes. Efeitos adversos, em sua maioria leves, ocorreram pelo menos uma vez durante o tratamento em $53 \%$ dos pacientes. Seis pacientes interromperam o tratamento, mas não houve nenhum caso de resistência secundária.
\end{abstract}

PALAVRAS-CHAVE: toxina botulínica, blefaroespasmo, distonia.

Botulinum toxin (BTX) blocks the release of acetylcholine at the neuromuscular junction leading to a state of muscle paralysis that may last for months ${ }^{1}$. It is considered as the most potent biological neurotoxin, causing high morbidity and death. This fact led to misconception of the toxin in the past ${ }^{2}$. However, over the past decade a complete renewal of its image took place and nowadays botulinum toxin is widely know as a therapeutic agent with multiple indications ${ }^{3}$, specially after being widely marketed to the public as an antiwrinkle tool for facial cosmetics. Nevertheless, it has revolutionized the treatment of many chronic neurological disorders with marked improvement in the quality of life and disability due to spasticity, hemifacial spasm, spasmodic dysphonia, hyperhidrosis, as well as many dystonic conditions. In Brazil, BTX was licensed for the treatment of various movement disorders in 1992, and has been successfully used in the management of blepharospasm (BP). Before the advent of this treatment, BP was considered a disabling condition with poor response to oral medications. Because it is a chronic disease, it is important to ensure that the treatment strategies are both safe and effective after long periods of maintenance, and that the patients report satisfaction with the lengthy treatment.

Since there are no previous reports regarding

${ }^{1}$ Fellow, Movement Disorders Clinic of the Department of Neurology, Hospital das Clínicas, University of São Paulo School of Medicine, São Paulo SP, Brazil (HC - FMUSP), ${ }^{2}$ Coordinator, Movement Disorders Clinic of the Department of Neurology, HC - FMUSP Received 3 June 2004, received in final form 15 September 2004. Accepted 6 November 2004. 
the long-term effects of BTX in the treatment of blepharoespasm in our country, the aim of this article is to describe our findings after 10-year experience.

\section{METHOD}

A retrospective analysis was conducted from data of 30 patients, who received botulinum neurotoxin type A (Botox-Allergan) at the Movement Disorders Clinic of the Department of Neurology, Hospital das Clínicas, University of São Paulo School of Medicine (HC-USPSM) over the past 10 years (1993 to 2003), to describe the long-term efficacy and side effects of the treatment of blepharospasm with BTX. The past medical history of the patients regarding comorbidities and previous use of oral medication or surgical procedures were reported.

The scheme of injection was performed according to a 10 symmetrical points modified from an original scheme proposed by Consky ${ }^{4}$ (Fig 1). Sites of injection were sometimes changed depending on the effects of the toxin achieved after each application, either to enhance its efficacy or to decrease collateral effects. The dose at the first application was usually 5 units per point. In the following injections the dose was calculated based on the therapeutic response and tolerance.

The efficacy of the application was evaluated by the

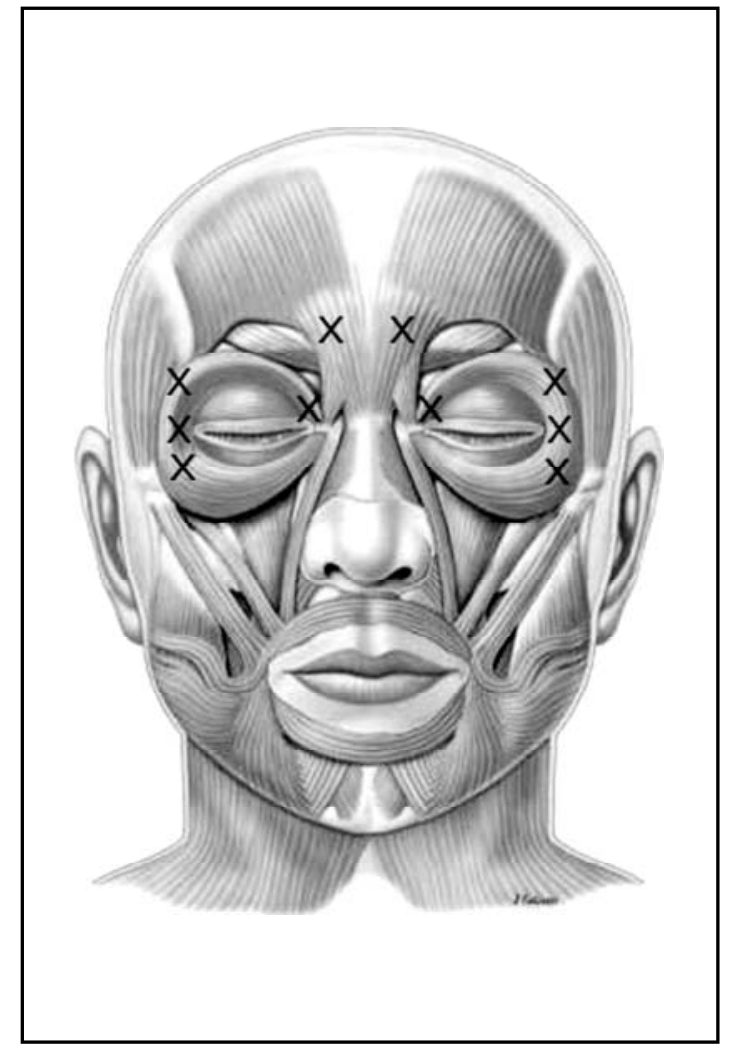

Fig 1. Injection points scheme for the treatment of blepharospasm used in the HC - FMUSP.

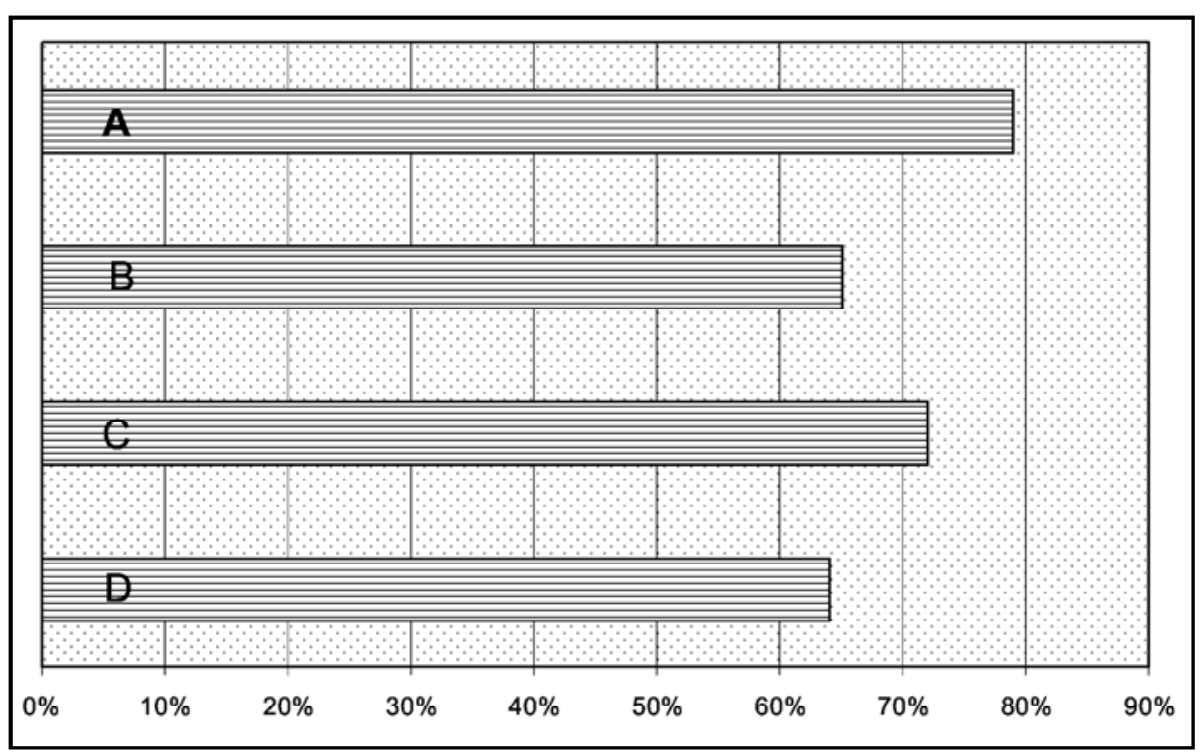

Fig 2. Response to BTX applications. The data is displayed in bars showing the results in differ ent moments of the follow-up. Bars: A) Current response of the patients who achieved more than 10 years of follow-up. B) Last registered application response of all patients. C) Current response of all the patients still on follow-up. D) First application response of all patients. Statistical analy sis was performed comparing bars $B, C$ and $D$ to observe changes in response over time. There was no significant difference between the response to the first and the last application regis tered for each patient (bars $D$ and $B ; p=0.7632$ according to a paired Student $t$ test) or between the response to the first application for all patients and the current average response in patients who are still on follow-up (bars $D$ and $C ; p=0.2365$ according to a non-paired Student $t$ test). 
patient based on a scale of subjective degree of functional impairment (Columbia University Rating Scale) ${ }^{5}$. Duration of the effect was also recorded and it was reported by the patient as the time of maximum effect, not including residual effects once its duration was much longer, and many times lasting until the next application. The interval between injections was established according to the duration of effect observed on previous injections. Both the dosage and interval between each application respected the general recommendations for minimizing the risk of BTX antibody formation in the treatment of neurological conditions ${ }^{6-8}$. General rules for each procedure were: usage of minimum dose that achieved best efficacy; avoidance of booster injections; longest interval tolerated and not shorter than 3 months. Prevalence of collateral effect was reported by each patient in an all-or-none variable that would point to its occurrence at least once during the treatment.

\section{RESULTS}

A total of 379 treatments with multiple site injections of BTX were administered to 30 patients with BP in a 10-year period. The mean age of the patients at the onset of the symptoms was 53.1 years (SD 9.87) and the mean age at the begging of the treatment was 58 years; $80 \%$ of them were female. Twenty two per cent of the patients met criteria for Meige syndrome (dystonic hyperactivity affecting not only the periocular muscles but also muscles of the lower part of the face, such as perioral, jaw and platismal muscles ${ }^{9}$ ), and $23 \%$ of them had dystonia affecting other cranial or cervical regions, mainly cervical dystonia ( $66 \%$ of these patients). Previously to the BTX treatment $63 \%$ of the patients had used oral medication for dystonia (73\% used biperiden, $63 \%$ used some benzodiazepine, $21 \%$ used baclofen; other drugs were used by a minority of patients). Only $15 \%$ of these patients reported good response with oral drugs.

Ninety three per cent of the patients showed significant improvement with the first BTX injection. The average improvement at the first application for those who responded was $69 \%$. The average response to the injections for those who took oral medications previously to BTX treatment was $74 \%$ and for those who did not use medications $62 \%$; however, this difference was analyzed using the Student t test and revealed to be not significant $(p=0.5272)$. The mean time of follow-up was 4.95 years, average of 12.63 applications per patient, and 60.93 units per application (SD=19.38). The mean duration of improvement was 2.64 months. The average benefit reported at the last application of all patients still on follow-up was $71.96 \%$. Five patients achieved 10 years of followup, in those the mean response for the last application was more than $10 \%$ higher than the response to the first application, but this difference was not analyzed due to the small number of patients. In general, there was no decrement in response for the patients during the follow-up period as can be seen in Fig 2.

Adverse effects, mostly minor, developed at least once during the treatment in $53 \%$ of patients, the most frequent was ptosis $(81 \%)$ followed by diplopia (12.5\%). Six patients $(20 \%)$ discontinued treatment for diverse reasons. Of these, 3 presented primary resistance. Two of them had eye-opening apraxia confirmed by eletroneuromyography. One patient had only 1 application with no result, and abandoned treatment. There was no case of secondary resistance. One patient who did not responded adequately to BTX injections in the beginning of her treatment was referred to a neurectomy and after this procedure presented satisfactory response to BTX applications with an average response rate of $60 \%$.

\section{DISCUSSION}

Results evidenced that BTX injections offered very good response rate with sustained effects while the use of oral medication was highly unsatisfactory and did not interfere with the response to the BTX treatment. In our opinion, a trial of oral medication (also suggested in literature ${ }^{10}$ ) is recommended since in public services the waiting list for the BTX treatment is usually very long.

In the literature some authors published similar results of long-term treatments for different neurological movement disorders ${ }^{11,12}$, hyperhydrosis $^{13}$, as well as other disease ${ }^{14}$. About blepharospasm, there were some cases included in large treatment series for diverse neurological disorders and their results resembled the ones observed in the present study ${ }^{15}$. Concerns about long-term use of BTX in the muscle can be refuted since Borodic ${ }^{16}$ showed no irreversible muscle atrophy in histological analysis of orbicularis oculi muscles of 11 patients who had received botulinum toxin over 3.5 years.

The apparent high rate of adverse effects (53\%) can be explained in this analysis since collateral effects were scored if they manifested at least once. This contrasts other data from the literature ${ }^{17}$ which consider the proportion of injections related to the 
collateral effect among the total number of injections in a short period. This tends to reduce the percentage of reported adverse effects since they can be avoided with changes in the procedure then decreasing the rate of collateral effects in future injections. Nevertheless, collateral effects were well tolerated in our series and were not related to abandonment of treatment. Ptosis is related to the action of BTX on levator palpebrae muscle, while diplopia is more uncommon and is usually related to the effect of BTX in lateral rectus mus$\mathrm{Cle}^{18}$, either for excessive diffusion of the toxin or misplacement of the application points in the superior palpebrae. Both can be avoided by correction of the injection site, decrease in the dosage or dilution. Ptosis can be prevented avoiding the central portion of the eyelid and diplopia by placing the needle more laterally to the injection site. Eyeopening apraxia, although fairly uncommon, has been previously related to BTX resistance ${ }^{19}$, and in our series, the patients drop out the treatment. Although secondary resistance to blepharospasm treatment with botulinum toxin has been already reported in the literature ${ }^{20}$, none of our patients had this evolution.

Overall, the results showed that BTX was a safe and effective treatment for blepharospasm and most of the side effects were well tolerated. Levels of response in the present study were comparable to those achieved in general literature. In those series, most of the patients referred subjective degree of improvement between $70 \%$ and $90 \%{ }^{20}$. Discontinuation for diverse reasons was also low after 10 years of follow-up. In our series, efficacy was maintained after long periods of treatment with high degree of patient satisfaction.

Acknowledgement - For his help in the analysis of data from the patients we thank Dr. Alexandre Maria
Santos from the Department of Neurology, Division of Neurosurgery, Hospital das Clínicas, University of São Paulo School of Medicine.

\section{REFERENCES}

1. MooreP. General and clinical aspects of treatment with botulinum toxin. In Handbook of botulinum toxin treatment. Oxford: Blackwell Science, 1995:28-54.

2. Erbguth FJ. Historical notes on botulism, Clostridium botulinum, botulinum toxin, and the idea of the therapeutic use of the toxin. Mov Disord 2004;19(Supp 8):S2-S6.

3. Misra VP The changed image of botulinum toxin. Br Med J 2002;325:1188.

4. Workshop: "Treinamento para aplicação de toxina botulínica em distonias e espasmo hemifacial", ministrado pelo Dr Earl Consky no Departamento de Neurologia da Escola Paulista de Medicina, São Paulo: 1991.

5. Barbosa ER, Silva HCA, Haddad MS, Bittar MS. Blefaroespasmo: tratamento com toxina Botulínica. Rev Hosp Clin Fac Med S Paulo 1996;51:220-223.

6. Zuber M, Sebald M, Bathien N, et al. Botulinum antibodies in dystonic patients treated with type A botulinum toxin: frequency and significance. Neurology 1993;43:1715-1718.

7. Dressler D. Clinical presentation and management of antibody-induced failure of botulinum toxin therapy. Mov Disord 2004;19(Supp 8):S92S100.

8. Jankovic J, Schwartz K. Response and immunoresistance to botulinum toxin injections. Neurology 1995;45:1743-1746.

9. Tolosa E, Marti MJ. Blepharospasm-oromandibular dystonia syndrome (Meige's syndrome): clinical aspects. Adv Neurol 1988;49:73-84.

10. Jankovic JJ, Tolosa E. Parkinson's disease and movement disorders, Fourth Edition, Philadelphia: Lippincott Williams \& Wilkins, 2002:331-364.

11. Defazio G, Abbruzzese G, Girlanda P, et al. Botulinum toxin A treatment for primary hemifacial spasm: a 10-year multicenter study. Arch Neurol 2002;59:418-420.

12. Tan EK, Jankovic J. Botulinum toxin A in patients with oromandibular dystonia: long-term follow-up. Neurology 1999;53:2102-2107.

13. Schnider P, Moraku E, Kittler H, et al. Treatment of focal hyperhidrosis with botulinum toxin type A: long-term follow up in 61 patients. Br J Dermatology 2001;145:289-293.

14. D'Onofrio V, Miletto P, Leandro G, Iaquinto G. Long-term follow-up of achalasia patients treated with botulinum toxin. Dig Liver Dis 2002;34:105-110.

15. Hsiung G-Y, Das SK, Ranawaya R, Lafontaine AL, Sucherowsky O. Longterm efficacy of botulinum toxin A in the treatment of various disorders over a 10 year-period. Mov Disord. 2002;17:1288-1293.

16. Borodic GE, Ferrante R. Effects of repeated botulinum toxin injections on orbicularis oculi muscle. J Clin Neuroophthalmol 1992;12:121-127.

17. Naumann M, Moore AP. Long-term safety of botulinum toxin type A. Mov Disord. 2003;18:1080-1081.

18. Dressler D. Botulinum toxin therapy. New York:Thieme, 2000:39-93.

19. Krack P, Marion MH. "Apraxia of lid opening" a focal eyelid dystonia: clinical study of 32 patients. Mov Disord. 1994;9:610-615.

20. Dressler D. Complete secondary botulinum toxin therapy failure in blepharospasm. J Neurol 2000;247:809-810. 